Acta Crystallographica Section C

Crystal Structure

Communications

ISSN 0108-2701

\section{Polymorphs of anhydrous theo- phylline: stable form IV consists of dimer pairs and metastable form I consists of hydrogen-bonded chains}

\author{
Dikshitkumar Khamar, ${ }^{a}$ Robin Gavin Pritchard, ${ }^{\mathrm{b}}$ Ian James \\ Bradshaw, ${ }^{a}$ Gillian Ann Hutcheon ${ }^{\mathrm{a}}$ and Linda Seton ${ }^{\mathrm{a} *}$
}

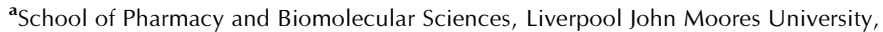
Byrom Street, Liverpool L3 3AF, England, and ${ }^{\mathbf{b}}$ School of Chemistry, University of Manchester, Brunswick Street, Manchester M13 9PL, England

Correspondence e-mail: I.seton@ljmu.ac.uk

Received 22 September 2011

Accepted 10 November 2011

Online 19 November 2011

The structure of a previously unreported polymorph of anhydrous theophylline (1,3-dimethyl-3,7-dihydro- $1 \mathrm{H}$-purine-2,6-dione), $\mathrm{C}_{7} \mathrm{H}_{8} \mathrm{~N}_{4} \mathrm{O}_{2}$, has been determined at $100 \mathrm{~K}$ and shown to have monoclinic symmetry with $Z^{\prime}=2$. The structure is named form IV and experimental observation indicates that this is the stable form of the material. The molecular packing consists of discrete hydrogen-bonded dimers similar to that observed in the monohydrate structure. The structure of form I has also been determined and consists of hydrogen-bonded chains.

\section{Comment}

Theophylline, (1), is a bronchodilator used to treat asthma in an oral dosage form. The hydration behaviour and solid-state chemistry have been studied (Wikstroem et al., 2008; Amado et al., 2007) and the compound is known to exist as a monohydrate form (form $M$; Sun et al., 2002), and three anhydrous polymorphs, viz. forms I, II and III, have also been reported (Ebisuzaki et al., 1997; Suzuki et al., 1989; Matsuo \& Matsuoka, 2007). Theophylline has been shown to convert between the monohydrate and anhydrous form II depending on the humidity or water activity of the solvent environment (Zhu et al., 1996). The pharmaceutical properties of both the anhydrous and monohydrate material have been studied and shown to differ (Phadnis \& Suryanarayanan, 1997).

Monohydrate form $M$ has a channel hydrate structure which has been shown to lose water, either in low humidity or at temperatures above $353 \mathrm{~K}$, to produce form II anhydrous material (Zhu et al., 1996; Ticehurst et al., 2002). The monohydrate packing [Sun et al., 2002; Cambridge Structural Database (CSD; Allen, 2002) refcode THEOPH01] consists of hydrogen-bonded dimer pairs which link via further hydrogen bonding with water molecules to form chains.
The form II structure has been determined (Ebisuzaki et al., 1997; CSD refcode BAPLOT01) and consists of two bifurcated $\mathrm{C}-\mathrm{H} \cdots \mathrm{O}$ hydrogen bonds and one $\mathrm{N}-\mathrm{H} \cdots \mathrm{N}$ hydrogen bond. The molecules join via these bonds to form chains. Unlike the monohydrate, there are no discrete dimers present in the crystal structure of form II.<smiles>Cn1c(=O)c2[nH]cnc2n(C)c1=O</smiles>

(1)

Form $\mathrm{I}$ is reported to be the stable form at higher temperatures. Its powder pattern has been presented in the literature (Suzuki et al., 1989), but its structure has not been reported previously.

Form III is a highly metastable form and rapidly converts to form II. Its powder pattern has been reported (Matsuo \& Matsuoka, 2007) but its structure has not been obtained owing to its metastable nature.

Recently, a fourth anhydrous polymorph of theophylline was identified (Seton et al., 2010). Form IV occurs as a result of slow, solvent-mediated conversion from form II or form I, and is therefore identified as the most thermodynamically stable anhydrous polymorph of theophylline. Form IV can be identified from its plate-like hexagonal morphology, distinct from the elongated morphology observed in particles of forms I, II and the monohydrate. On heating, form IV does not melt but undergoes solid-state conversion to form II at $483-513 \mathrm{~K}$ (Khamar et al., 2011). This paper presents the structure of this previously unreported anhydrous polymorph of theophylline, and the structure of the high-temperature anhydrous polymorph, form I.

The structure of form IV is monoclinic and, unlike the other anhydrous polymorphs, has two molecules in its asymmetric unit, as shown in Fig. 1. These two molecules form a dimer pair with an $R_{2}^{2}(10)$ motif (Bernstein et al., 1995) via $\mathrm{N} 2-$ $\mathrm{H} 2 \cdots \mathrm{O} 11$ and $\mathrm{N} 12-\mathrm{H} 12 \cdots \mathrm{O} 1$ hydrogen bonds. A short
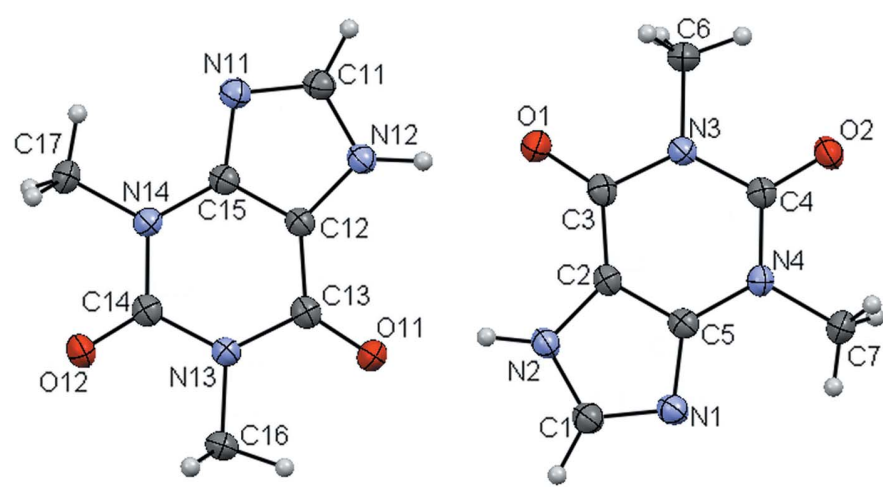

Figure 1

A view of the two independent molecules in the asymmetric unit of form IV. Displacement ellipsoids are drawn at the $50 \%$ probability level and $\mathrm{H}$ atoms are shown as spheres of arbitrary radii. 


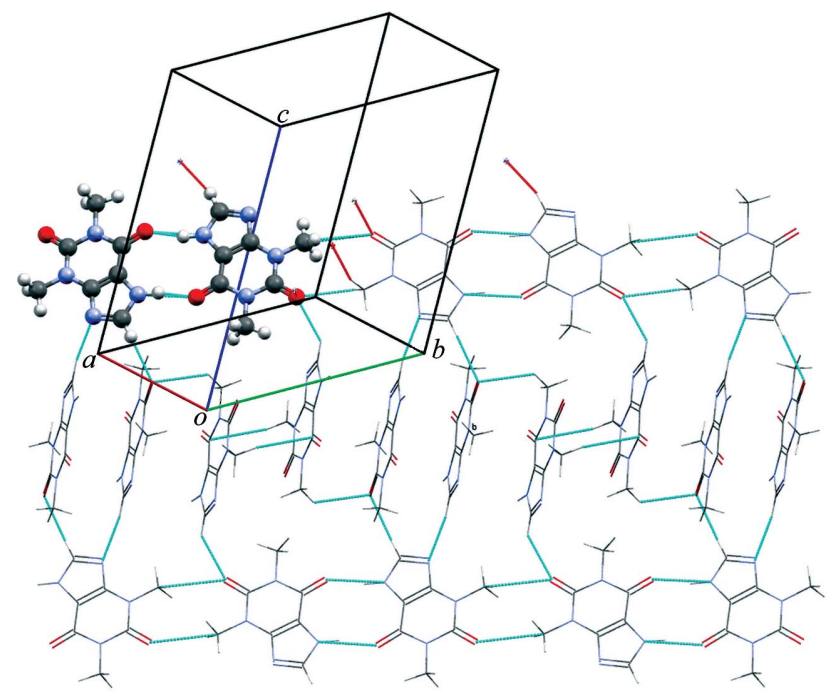

(a)

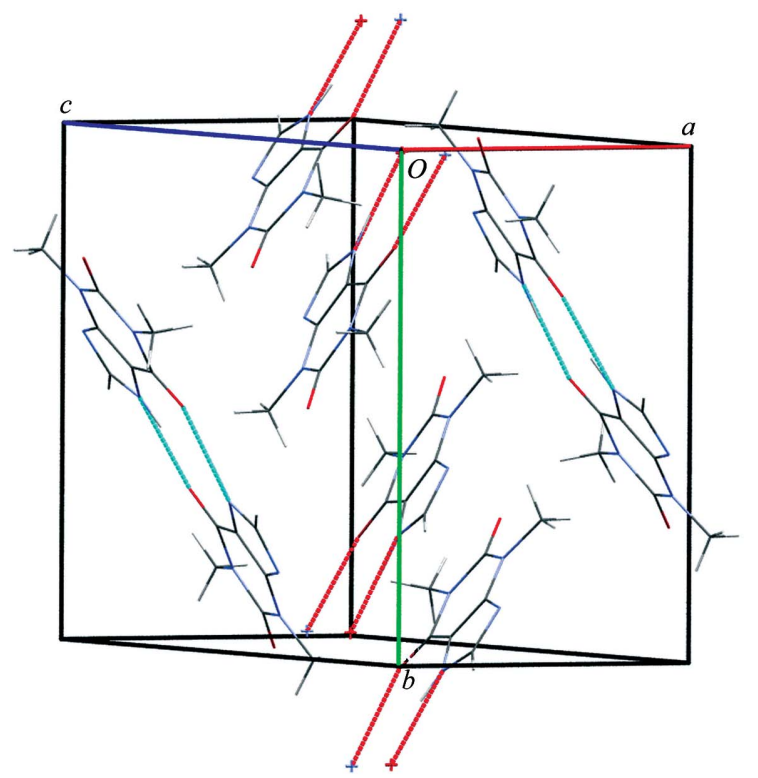

(b)

Figure 2

(a) The structure of form IV is built from hydrogen-bonded dimers which are linked via close contacts to form extended chains. The chains form close contacts with each other to make an extended network structure. (b) The rings of the molecule also stack in a $\pi-\pi$ fashion.

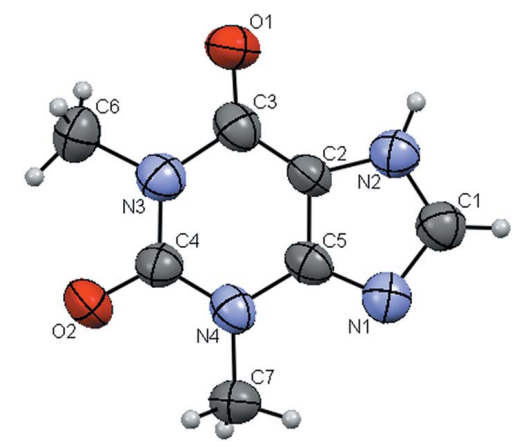

Figure 3

The asymmetric unit of form I. Displacement ellipsoids are drawn at the $50 \%$ probability level and $\mathrm{H}$ atoms are shown as spheres with arbitrary radii.

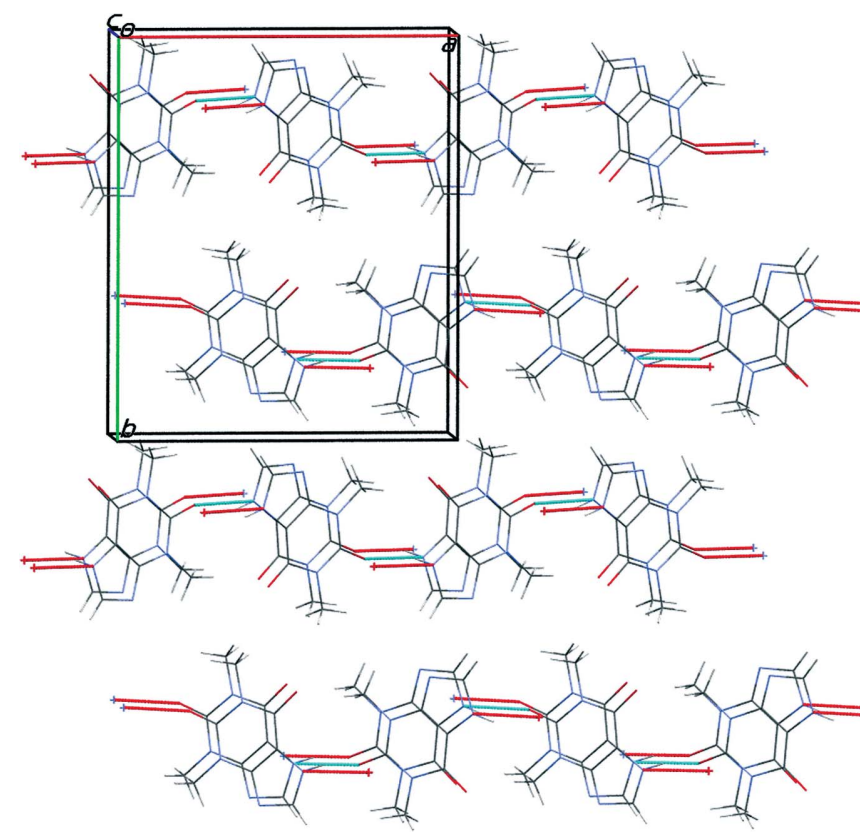

Figure 4

A projection of form I down the $c$ axis, showing the chain motif. Hydrogen bonds are indicated by broken lines. The chains are discrete, having no hydrogen bonds linking them.

contact is formed by donation via $\mathrm{C} 11-\mathrm{H} 11 \cdots \mathrm{O} 2\left(-x, y-\frac{1}{2}\right.$, $\left.-z+\frac{1}{2}\right)$ and a second by accepting via $\mathrm{N} 11$ at $\left(x,-y+\frac{1}{2}, z+\frac{1}{2}\right)$ a short contact from $\mathrm{C} 1-\mathrm{H} 1$. These short contacts link the dimers into a two-dimensional network parallel to the (110) plane. In addition, there are $\pi-\pi$ stacking interactions between the fused rings of pairs of molecules of the same unique type (atoms $\mathrm{O} 1$ to $\mathrm{C} 8$ ). The centroid-centroid distance between the five-membered and opposing six-membered rings is 3.3686 (12) $\AA$, with an interplanar angle of $0.17(11)^{\circ}$.

The hydrogen-bonding pattern of the basic nitrogen $(\mathrm{N}$ in the imidazole ring) is interesting. It is a good acceptor according to Etter's rules (Etter, 1990), but because of insufficient donors, only atom N11 of the asymmetric unit is involved in a contact and not N1. These short contacts link the dimers into chains, and chains of dimers stack in layers related by an inversion centre, as displayed in Fig. 2. This dimerization is similar to the packing motif observed in the monohydrate structure and in a number of cocrystals of theophylline (Trask et al., 2006) and may account for the thermodynamic stability of the structure compared with the chain motif of form II.

Both forms I and II are known to immediately convert to the monohydrate on contact with water (Suzuki et al., 1989) and therefore the monohydrate structure is considered to be the most thermodynamically stable structure for the theophylline molecule in an aqueous environment. It is not unreasonable therefore that the dimer-based structure of form IV, containing the same dimer pair motif as the monohydrate, is the most thermodynamically stable of the observed anhydrous forms. It has been observed that, like forms I and II, form IV will convert to the monohydrate on contact with water, further stability being conferred by the hydrogen bonding of the dimer pairs with the water molecules. 
The asymmetric unit of the high-temperature polymorph, form I, is shown in Fig. 3. The structure consists of extended chains formed by hydrogen bonding between $\mathrm{N} 2-\mathrm{H} 2$ and $\mathrm{O} 2\left(-\frac{1}{2}+x, \frac{1}{2}-y,-1+z\right)$, as shown in Fig. 4. Chains are joined by a weak contact from $\mathrm{C} 1-\mathrm{H} 1 \cdots \mathrm{N} 1\left(-x, 1-y,-\frac{1}{2}+z\right)$ which has the effect of generating a three-dimensional network. The hydrogen-bonded chains run parallel to the (201) plane and are stacked with a $\pi-\pi$ interaction between the fused rings of adjacent molecules related by translation along the $c$ axis. The centroid-centroid distance between the strictly parallel five-membered rings is 3.854 (7) $\AA$, with an offset of $1.871 \AA$, and between the six-membered rings the centroid-centroid distance is 3.703 (6) $\AA$.

\section{Experimental}

Anhydrous theophylline purchased from Sigma Aldrich UK was identified as form II and used as received. To prepare form IV, a saturated solution of theophylline was prepared by suspending excess form II in a methanol-water mixture $(9: 1 v / v)$ for $1 \mathrm{~h}$ at $318 \mathrm{~K}$ and then filtering with a syringe filter of $0.45 \mu \mathrm{m}$ size. The filtered solution was cooled to room temperature. After $1 \mathrm{~h}$, needle-like crystals were observed which were held in contact with the mother liquor for two months. Over this period, the morphology of the crystals was observed to change, with hexagonal plates being observed after several days, indicating the solvent-mediated transformation to form IV. Form I could not be obtained by solution methods and was prepared by heating form II in glass vials at $538-541 \mathrm{~K}$ for $2 \mathrm{~h}$. The crystals undergo solid-state conversion and in doing so the parent crystal laminates to produce very fine needles of form I. The quality of the crystals was poor; they contained cracks and defects introduced during the phase transition.

\section{Form IV}

\section{Crystal data}

$\mathrm{C}_{7} \mathrm{H}_{8} \mathrm{~N}_{4} \mathrm{O}_{2}$

$M_{r}=180.17$

Monoclinic, $P 2_{1} / c$

$a=7.7055$ (1) А

$b=13.0010$ (2) $\AA$

$c=15.7794(3) \AA$

$\beta=103.224(1)^{\circ}$

\section{Data collection}

Nonius KappaCCD area-detector diffractometer

Absorption correction: multi-scan (SORTAV; Blessing, 1989)

$T_{\min }=0.971, T_{\max }=0.991$

Table 1

Hydrogen-bond geometry $\left(\AA,^{\circ}\right)$ for IV.

\begin{tabular}{lllll}
\hline$D-\mathrm{H} \cdots A$ & $D-\mathrm{H}$ & $\mathrm{H} \cdots A$ & $D \cdots A$ & $D-\mathrm{H} \cdots A$ \\
\hline $\mathrm{N} 2-\mathrm{H} 2 \cdots \mathrm{O} 11$ & $0.97(3)$ & $1.80(3)$ & $2.736(2)$ & $163(3)$ \\
$\mathrm{N} 12-\mathrm{H} 12 \cdots \mathrm{O} 1$ & $0.98(3)$ & $1.80(3)$ & $2.759(2)$ & $168(3)$ \\
$\mathrm{C} 1-\mathrm{H} 1 \cdots \mathrm{N} 11^{\mathrm{i}}$ & $1.00(2)$ & $2.29(2)$ & $3.266(3)$ & $165(2)$ \\
$\mathrm{C} 11-\mathrm{H} 11 \cdots \mathrm{O} 2^{\mathrm{ii}}$ & $1.00(3)$ & $2.38(3)$ & $3.222(3)$ & $141(2)$ \\
\hline
\end{tabular}

Symmetry codes: (i) $x,-y+\frac{1}{2}, z+\frac{1}{2}$; (ii) $-x, y-\frac{1}{2},-z+\frac{1}{2}$.
Refinement

$R\left[F^{2}>2 \sigma\left(F^{2}\right)\right]=0.050$

$w R\left(F^{2}\right)=0.138$

$S=1.07$

3023 reflections

300 parameters

All $\mathrm{H}$-atom parameters refined

$\Delta \rho_{\max }=0.25{\mathrm{e} \AA^{-3}}^{-3}$

$\Delta \rho_{\min }=-0.32 \mathrm{e}^{-3}$

\section{Form I}

Crystal data

$\mathrm{C}_{7} \mathrm{H}_{8} \mathrm{~N}_{4} \mathrm{O}_{2}$

$M_{r}=180.17$

Orthorhombic, Pna $_{1}$

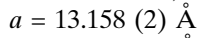

$b=15.630$ (3) $\AA$

$c=3.854$ (1) $\AA$

$V=792.6(3) \AA^{3}$

$Z=4$

Mo $K \alpha$ radiation

$\mu=0.12 \mathrm{~mm}^{-1}$

$T=100 \mathrm{~K}$

$0.25 \times 0.06 \times 0.03 \mathrm{~mm}$

\section{Data collection}

Nonius KappaCCD area-detector diffractometer

Absorption correction: multi-scan (SORTAV; Blessing, 1989)

$T_{\min }=0.972, T_{\max }=0.997$

Refinement

$R\left[F^{2}>2 \sigma\left(F^{2}\right)\right]=0.088$

$w R\left(F^{2}\right)=0.202$

$S=0.98$

764 reflections

120 parameters

1 restraint

1246 measured reflections 764 independent reflections 462 reflections with $I>2 \sigma(I)$ $R_{\text {int }}=0.040$

Table 2

Hydrogen-bond geometry $\left(\AA{ }^{\circ}\right)$ for form I.

\begin{tabular}{lllll}
\hline$D-\mathrm{H} \cdots A$ & $D-\mathrm{H}$ & $\mathrm{H} \cdots A$ & $D \cdots A$ & $D-\mathrm{H} \cdots A$ \\
\hline $\mathrm{N} 2-\mathrm{H} 2 \cdots \mathrm{O} 2^{\mathrm{i}}$ & 0.88 & 1.92 & $2.743(11)$ & 155 \\
$\mathrm{C} 1-\mathrm{H} 1 \cdots \mathrm{N} 1^{\mathrm{ii}}$ & 0.95 & 2.41 & $3.267(12)$ & 150 \\
\hline
\end{tabular}

Symmetry codes: (i) $x-\frac{1}{2},-y+\frac{1}{2}, z-1$; (ii) $-x,-y+1, z-\frac{1}{2}$.

The positions of the $\mathrm{H}$ atoms of form IV were refined freely with freely refined individual isotropic displacement parameters. The $\mathrm{H}$ atoms of form I were constrained with $\mathrm{N}-\mathrm{H}, \mathrm{C} 1-\mathrm{H} 1$ and $\mathrm{C}-$ $\mathrm{H}$ (methyl) distances of $0.88,0.95$ and $0.98 \AA$, respectively, with $U_{\text {iso }}(\mathrm{H})=1.5 U_{\text {eq }}(\mathrm{C})$ for the methyl groups and $1.2 U_{\text {eq }}(\mathrm{C}, \mathrm{N})$ otherwise.

The quality of the form I crystals, which were obtained by solidstate conversion, was poor. The best crystal was selected from several samples but it was not possible to obtain a high-quality crystal without defects. The dimensions of the crystals were such that data collection was only just possible. The crystal diffracted poorly and reflection intensity was extremely weak so that a scan time greater than $30 \mathrm{~h}$ produced $90 \%$ completion. Further collection was not possible due to the quality and size of the crystal.

For both compounds, data collection: COLLECT (Hooft, 1998); cell refinement: SCALEPACK (Otwinowski \& Minor, 1997); data reduction: DENZO (Otwinowski \& Minor, 1997) and SCALEPACK; program(s) used to solve structure: SIR92 (Altomare et al., 1994); program(s) used to refine structure: SHELXL97 (Sheldrick, 2008); molecular graphics: ORTEP-3 for Windows (Farrugia, 1997); software used to prepare material for publication: Win $G X$ (Farrugia, 1999). 
DK acknowledges the School of Pharmacy and Biomolecular Sciences, LJMU, for funding.

Supplementary data for this paper are available from the IUCr electronic archives (Reference: BM3111). Services for accessing these data are described at the back of the journal.

\section{References}

Allen, F. H. (2002). Acta Cryst. B58, 380-388.

Altomare, A., Cascarano, G., Giacovazzo, C., Guagliardi, A., Burla, M. C., Polidori, G. \& Camalli, M. (1994). J. Appl. Cryst. 27, 435.

Amado, A. M., Nolasco, M. M. \& Ribeiro-Claro, P. J. A. (2007). J. Pharm. Sci. 96, 1366-1379.

Bernstein, J., Davis, R. E., Shimoni, L. \& Chang, N.-L. (1995). Angew. Chem. Int. Ed. Engl. 34, 1555-1573.

Blessing, R. H. (1989). J. Appl. Cryst. 22, 396-397.

Ebisuzaki, Y., Boyle, P. D. \& Smith, J. A. (1997). Acta Cryst. C53, 777-779.

Etter, M. (1990). Acc. Chem. Res. 23, 120-126.

Farrugia, L. J. (1997). J. Appl. Cryst. 30, 565.
Farrugia, L. J. (1999). J. Appl. Cryst. 32, 837-838.

Flack, H. D. (1983). Acta Cryst. A39, 876-881.

Hooft, R. W. W. (1998). COLLECT. Nonius BV, Delft, The Netherlands.

Khamar, D., Bradshaw, I. J., Hutcheon, G. A. \& Seton, L. (2011). Cryst. Growth Des. doi:10.1021/cg2008478.

Matsuo, K. \& Matsuoka, M. (2007). Cryst. Growth Des. 7, 411-415.

Otwinowski, Z. \& Minor, W. (1997). Methods in Enzymology, Vol. 276, Macromolecular Crystallography, Part A, edited by C. W. Carter Jr \& R. M. Sweet, pp. 307-326. New York: Academic Press.

Phadnis, N. V. \& Suryanarayanan, R. (1997). J. Pharm. Sci. 86, 1256-1263.

Seton, L., Khamar, D., Bradshaw, I. J. \& Hutcheon, G. A. (2010). Cryst. Growth Des. 10, 3879-3886.

Sheldrick, G. M. (2008). Acta Cryst. A64, 112-122.

Sun, C., Zhou, D., Grant, D. J. W. \& Young, V. G. (2002). Acta Cryst. E58, o368-o370.

Suzuki, E., Shimomura, K. \& Sekiguchi, K. (1989). Chem. Pharm. Bull. 37, 493-497.

Ticehurst, M. D., Storey, R. A. \& Watt, C. (2002). Int. J. Pharm. 247, 1-10.

Trask, A. V., Motherwell, W. D. S. \& Jones, W. (2006). Int. J. Pharm. 320, 114123.

Wikstroem, H., Rantanen, J., Gift, A. D. \& Taylor, L. S. (2008). Cryst. Growth Des. 8, 2684-2693.

Zhu, H. J., Yuen, C. M. \& Grant, D. J. W. (1996). Int. J. Pharm. 135, 151-160. 